\title{
The relationship between mental disorder and violence
}

\author{
BARBARA LAY 1 \\ I Department for Psychiatry, Psychotherapy and Psychosomatics University, Hospital of Psychiatry Zurich, Switzerland.
}

Received: 1/13/2015 - Accepted: 1/26/2015

DOl: 10.1590/0101-60830000000043

Lay B / Arch Clin Psychiatry. 2015;42(1):31-2

\section{Dear Editor,}

The letter to the editor "Patricide and schizophrenia - A case report"1, published in the last issue of the Archives of Clinical Psychiatry, addresses an issue that has always concerned forensic psychiatry, namely the relationship between mental disorder and violent crimes.

Besides this long-standing professional debate, such cases attract much attention in the mass media, which exposes us daily to movie depictions of crazed killers - linking violence to mental illness in the public perception by showing mental disorder in particular in the light of unpredictability and dangerousness ${ }^{2}$.

However, one shouldn't overlook the fact that most mentally ill people never commit violent crimes and schizophrenia is not a sufficient cause for violence. Besides, schizophrenia as a nosological construct encompasses most heterogeneous psychopathological conditions that vary considerably with respect to core signs and symptoms, psychiatric comorbidity and social adjustment.

It should be further kept in mind, that in contrast to the disturbing frequency of brutal crimes in the TV programmes, homicides in general are rare events in real life (the rates per 100,000 inhabitants as reported by $\mathrm{UNODC}^{3}$ are 3.0 for Europe, 4.7 for the USA, 25.2 for Brazil) and parricide in particular (usually not reported separately in official crime statistics) only comprises a small fraction (in the single digits) of these.

Against this background, the question arises of how an anecdotal case report like the one brought to our attention by Moscatello is to be seen in the context of existing scientific research. Four questions, in particular, are of public concern: (A) what is the causal role of severe mental illness in the occurrence of violence, (B) how much of the violence in the community can be attributed to mental illness, $(C)$ what are the factors that mediate between severe mental illness and behaving violently and (D) what could be done to reduce the violence.

There is converging evidence from numerous international studies that (A) the risk of antisocial behaviour and violent offence is increased, and that of homicides even markedly increased, in people with schizophrenia, compared to the general population ${ }^{4-6}$. This evidence, based on unselected birth cohorts, representative population studies and retrospective cohorts (schizophrenia patients; prison inmates), is quite robust and does not leave much room for controversial interpretations. Findings suggest e.g. that the risk of an individual with psychosis committing a violent offence is 2 to 6 times higher for men and 2 to 8 times higher for women of similar age, compared to the general population ${ }^{7}$. Five percent to $28 \%$ of those charged with murder in prisons in Western countries have been diagnosed with a schizophrenia spectrum disorder ${ }^{8,9}$. As for the population-attributable risk (B) research estimates the overall contribution of people with severe mental illness to violent crime to be between $2 \%$ and $10 \%$, with coexisting substance abuse substantially increasing the risk ${ }^{4}$.
Therefore, cases such as this, although extremely rare, are of high impact on the societal level. Moreover, despite considerable advances in care provision including antipsychotic medication in recent decades, the elevated risk of violent acts by severely mentally ill patients (with schizophrenia as well as personality disorders) has not been reduced. It has been hypothesized that still too few people with severe mental illness enter the mental health care system betimes, and that those who do remain there for a too short period ${ }^{8,10}$.

(C) In this particular case, there are several dispositional, historical and contextual factors which are well known to increase the risk of violence: the family history of severe mental illness and violence, and his long-standing aggressive behaviour and repeated violent assaults in the past, as mentioned by Moscatello, should have deserved attention. Such factors operating before and during periods of active illness have been identified as being pivotal to the prediction of violent acts and hence form an integral part of current forensic risk assessment tools ${ }^{11}$. (D) The crime reported therefore emphasizes the need, once again, to look beyond psychotic symptoms and to consider a patient's historical and current life situation more closely in order to prevent such serious assaults.

Moreover, it is well known that the vast majority of the victims of schizophrenic offenders are found among the closest relatives ${ }^{12}$. Family members are also the ones on whom most of the burden of care for those with serious mental diseases is placed. Efforts to address the risk of violence therefore have to increase the focus on these potential victims who should receive the necessary support and counsel from mental health professionals.

As for the further clinical implications, one has to agree with Moscatello conclusions, and even more so as the incidence of aggressive violence in schizophrenia can be reduced by intense mental health care and close supervision ${ }^{5,8}$. Treatment with antipsychotic drugs is indicated but in itself cannot guarantee non-violence. Special programmes of comprehensive psychiatric aftercare following discharge from general psychiatric or forensic hospitals which take into account illness history, psychosocial functioning and substance use are mandatory for patients with schizophrenia who engage in aggressive behaviour towards others - which is what experts have long been calling for. Data from large-scale studies, however, suggest that the care currently provided by general psychiatric services for these "difficult" severely mentally ill persons is mostly inadequate, if not - as in the present case - non-existent, and fails to reduce antisocial and criminal behaviours ${ }^{13}$.

The gap between scientific research and psychiatric practice thus could not be demonstrated more clearly than by this case. To prevent such tragedies we will have to integrate the current knowledge into mental health care - both, with regard to a careful and early risk assessment and the provision of evidence-based treatments that address the complex of problems of people with serious mental illness who are violent. 


\section{References}

1. Moscatello R. Patricide and schizophrenia - A case report. Arch Clin Psychiatry. 2014;41(6):159.

2. Stuart H. Violence and mental illness: an overview. World Psychiatry. 2003;2(2):121-4.

3. UNODC Homicide statistics 2013. Available at: http://www.unodc.org/ gsh/en/data.html. Retrieved: 2014-11-07.

4. Walsh E, Buchanan A, Fahy T. Violence and schizophrenia: examining the evidence. BJP. 2002;180:490-5.

5. Stadtland C, Nedopil N. Psychiatrische Erkrankungen und die Prognose krimineller Rückfälligkeit [Psychiatric disorders and the prognosis for criminal recidivism]. Nervenarzt. 2005;76(11):1402-11.

6. Hodgins S. Violent behaviour among people with schizophrenia: a framework for investigations of causes, and effective treatment, and prevention. Philos Trans R Soc Lond B Biol Sci. 2008;363(1503):2505-18.
7. Fazel S, Grann M. The population impact of severe mental illness on violent crime. Am J Psychiatry. 2006;163:1397-403.

8. Hodgins S. Gewalt und Kriminalität bei psychisch Kranken. Neuropsychiatrie. 2006;20(1):7-14

9. Mullen PE. Schizophrenia and violence: from correlations to preventive strategies. Adv Psychiatr Treat. 2006;12:239-48.

10. Kroeber HL. Forensische Psychiatrie - Ihre Beziehungen zur klinischen Psychiatrie und zur Kriminologie. Nervenarzt. 2005;76:1376-81.

11. Elbogen EB, Johnson SC. The intricate link between violence and mental disorder. Arch Gen Psychiatry. 2009;66(2):152-61.

12. Steadman HJ, Mulvey EP, Monahan J, Clark Robbins P, Appelbaum PS, Grisso T, et al. Violence by people discharged from acute psychiatric inpatient facilities and by others in the same neighborhoods. Arch Gen Psychiatry. 1998;55(5):393-401.

13. Hodgins $\mathrm{S}$. The interface between general and forensic psychiatric services. Eur Psychiatry. 2009;24:354-5. 